\title{
Life satisfaction, overweightness and obesity
}

\author{
Masanori Kuroki
}

\begin{abstract}
Many economists share the view that the rise in obesity is largely the result of rational decision-making by individuals who compare risks and benefits. A dominant view among economists is that there is no economic justification for government intervention unless there is a market failure. However, recent developments in behavioral economics suggests that people often fail to make optimal decisions, and that public welfare may be improved by government interventions even when there is no externality. This paper examines the association between one's body weight and life satisfaction by utilizing data on self-reported life satisfaction, which approximates individual utility, after briefly reviewing the economics of obesity and discussing the rationale and justification of obesity-related policies. Using a large data set $(\mathrm{N}=1,465,219)$, it is found that life satisfaction of people who are overweight or obese is lower. The adverse life satisfaction effect of obesity remains statistically significant, even when socioeconomic factors and obesity-related health variables are controlled. The findings suggest that many overweight and obese people may be making sub-optimal decisions when it comes to eating. While the findings are not causal and thus do not necessarily suggest that government intervention will be welfareenhancing even in the absence of negative externalities, effective anti-obesity policies may lead to higher life satisfaction among many overweight people who are struggling with self-control problems.
\end{abstract}

Keywords: obesity, overweight, BMI, life satisfaction, happiness

\section{Introduction}

It is well known that the prevalence of obesity is rising. In 2013, 70.7\% of American adults were overweight, and 37.9\% were obese (Centers for Disease Control and Prevention, 2015). In the United Kingdom, $61.7 \%$ of adults were overweight, and $25.6 \%$ were obese in 2014 (Public Health England, 2015). There is little question that obesity is detrimental to personal health, but whether obesity is a public health problem that calls for government intervention is contentious. Many economists view obesity as largely the result of rational decision-making by individuals who compare risks and benefits (Cutler et al., 2003), and a dominant view among economists is that there is no economic justification for government intervention unless there is a market failure. That is, even though governments may be able to encourage healthy eating by, say, taxing unhealthy foods, it has no more right to tax them than other foods if one's weight causes no harm to others.

However, recent developments in behavioral economics suggest that people often fail to make optimal decisions, and public welfare may be improved by government interventions even when there is no externality. These economists argue that utility gain from eating is often more than offset by the disutility from being overweight. This suggests that whether public actions to reduce obesity are justified depends not only on whether obesity imposes negative externalities, 
but also whether many people make decisions that are not consistent with their long-term preferences. Casual observations suggest that many people can rationally make plans but often cannot carry out those plans.

This paper examines the association between one's body weight and life satisfaction by utilizing data on self-reported life satisfaction, which approximates individual utility, after briefly reviewing the economics of obesity and discussing the rationale and justification of obesity-related policies. This paper's contribution is to use a large data set and document the association between overweight/obesity and wellbeing, which can be useful in determining whether government intervention can enhance wellbeing. If being overweight leads to lower utility, that suggests people's eating decisions may not be made optimally, due to their timeinconsistent preferences. In this case, government intervention may be justified even in the absence of externalities. If, on the other hand, being overweight does not lead to lower utility, it suggests that individuals are maximizing their inter-temporal utility - that is, people value current consumption of foods more than the future harm (such as increased risk of coronary heart disease and diabetes) and other personal costs (such as adverse labor market consequences and social stigma). In this case, government intervention is not justified unless there are externalities.

Using the data on approximately 1,465,000 individuals, I find that life satisfaction of people who are overweight or obese is lower. The adverse life satisfaction effect of obesity remains statistically significant even when socioeconomic factors and obesity-related health variables are controlled for. The findings suggest that many overweight and obese people may be making suboptimal decisions when it comes to eating. While the findings are not causal and thus do not necessarily suggest that government intervention will be welfare-enhancing even in the absence of negative externalities, effective anti-obesity policies may lead to higher life satisfaction among many overweight people who are struggling with self-control problems.

\section{The economics of obesity}

\subsection{An overview}

Several factors have been used to explain the growth in obesity. New technologies have lowered prices of calorie-dense foods and drinks relative to fruits and vegetables (Finkelstein et al., 2005). Technological innovations such as vacuum packaging and improved preservatives, and deep freezing have led to reductions in the time price of food and thus increased food consumption (Cutler et al., 2003). Among youths, a rise in the price of food at fast-food restaurants leads to improvements in obesity outcomes, while a rise in the price of fruit and vegetables leads to increased obesity (Grossman et al., 2014). People now expend fewer calories because manual labor has been replaced by more sedentary work, due to technological change (Lakdawalla \& Philipson, 2009). In short, economists have found that people are getting heavier because incentives to eat more or burn fewer calories have increased.

It may seem unreasonable to claim that people are getting heavier when rationally, the risk involves health issues such as heart disease and diabetes. In addition to the negative health consequences, obese people suffer in other dimensions of life. Being overweight may adversely affect labor market outcomes if (1) employers discriminate against overweight individuals, 
perhaps due to bias against overweight and obese people, ${ }^{1}$ and (2) being overweight lowers productivity through poor health and/or motivation due to the lower life expectancy of these people. ${ }^{2}$ Non-monetary costs include poor body image and low self-esteem, and there is robust evidence that being obese often leads to depression (Roberts et al., 2003). But there is a long tradition in economics that people are rational, and many economists view obesity as people simply trading off the utility from current food intake against the associated monetary expense and disutility of future weight gain and health. Eating is obviously a source of pleasure, and people trade off the long-term costs of overeating and eating fat and sugary foods against the immediate pleasure of eating such foods.

Even if obesity comes with adverse health consequences, one reason that people are getting heavier may be due to, as late Gary Becker (2005) put it, "the expectation that new drugs will greatly reduce the adverse consequences of being obese... [Many people] can rationally believe that in twenty years or so still newer drugs that control diabetes and other diseases will be developed... Then for anyone who likes to eat sugary and fat foods, it does not seem so irrational to do so when the consequences will be much less harmful to health than they are at present." That is, people with excess weight are not necessarily making mistakes in choosing their diet. Even if some foods may be addictive, addiction to food can be rational, as a decision-maker may rationally choose to become addicted by weighting present pleasure more than future harm (Becker \& Murphy, 1988; Dragone, 2009). A rise in obesity and obesity-related disease does not mean that people are worse off overall. Cutler et al. (2003) argue that most people are better off even if their weight has increased.

Several empirical studies have examined the effect of being overweight or obese on subjective wellbeing, which approximates individual utility, in economics. Oswald and Powdthavee (2007) document a negative association between BMI and life satisfaction using British and German data. Katsaiti (2012) finds that being obese negatively affects life satisfaction using the data from Germany, UK, and Australia. Forste and Moore (2012) find a negative association between adolescent body weight and life satisfaction. Böckerman et al. (2014) find that being obese does not affect subjective wellbeing once health and functional status are controlled, suggesting that the observed negative relationship between obesity and subjective wellbeing is mainly due to the adverse effects of obesity on health and functioning. Graham and Felton (2005) find that being overweight (relative to one's reference norm) increases the risk of depression, using the 1979 National Longitudinal Survey of Youth. As discussed below in detail, this study contributes to the literature by using a larger random sample of individuals $(\mathrm{N}=1,465,219)$ than the previous studies. $^{3}$

\footnotetext{
${ }^{1}$ Cawley (2004) finds that weight lowers wages for white females. Morris (2007) finds that obesity has a statistically significant and negative effect on employment in both males and females. Caliendo and Lee (2013) find that obese women (but not overweight women or overweight/obese men) experience labor market discrimination in Germany. Brunello and D'Hombres (2007) find that BMI decreases the real earnings of both men and women in Europe. Lindeboom et al. (2010) use an instrumental variable approach and find little effect of obesity on employment. One caveat is that it is possible that fat people may feel that they experience discrimination even if they are not actually discriminated against. Roehling et al. (2007) find that obese people are more likely to report employment discrimination.

${ }^{2}$ Of course, adverse labor market outcomes (low wages or unemployment) may lead to obesity if fat sugary food is an inferior good.

${ }^{3}$ Wadsworth and Pendergast (2014) also use the same data source (2005-2008 BRFSS) and find a negative association between obesity and life satisfaction, but they do not examine overweight individuals. In addition, in order to control for health, they use self-reported health, which is highly endogenous with life satisfaction. Relating a person's subjective assessment of one aspect of life to her assessment of another should be avoided in general (Hamermesh,
} 


\subsection{Anti-obesity policies}

Many government officials attempt to reduce obesity. ${ }^{4}$ Probably the most controversial policy proposed is a "fat tax," which is often criticized for being unfair and regressive. ${ }^{5}$ In the United States, many states already impose sale taxes on such categories of food as soft drinks, candy and snacks, such as chips and pretzels. ${ }^{6}$ In the UK, ice cream and potato chips are taxed (Gruber, 2007). The idea of taxing unhealthy foods has been raised from time to time (Jacobson \& Brownell, 2000; Brownell et al., 2009). However, Powell and Chaloupka (2009) review various studies and argue that "small taxes or subsidies were not likely to produce significant changes in BMI or obesity prevalence but that nontrivial pricing intervention might have a measurable effect on Americans' weight outcomes" (p. 249). Some local governments simply ban the sale of certain items. New York City has decided to ban large-size sodas and other sugary drinks being sold in restaurants and other eateries, and the city of Boston has decided to ban the sale, advertising, and promotion of sugary beverages on government property (City of Boston, 2011).

As the lack of perfect information can lead to suboptimal food decisions (Stigler, 1961), another type of policy increases the availability of nutrition information. The best-known example of such a policy is the Nutrition Labeling and Education Act (NLEA), which required nutrition information to be printed on packaged foods but not on restaurant menus. Recently, lawmakers have sought to require chain restaurants to post caloric information, but evidence suggests that providing more nutrition information is not effective in encouraging lower caloric intake (Liu et al., 2013). Downs et al. (2009) also point out that providing accurate calorie information may lead to perverse effects, as dieters who have overestimated their calorie intake may decide to consume more food now that they have realized that they can eat more and still keep their goals.

There are several other policy ideas that have been motivated by behavioral economics. Liu et al. (2013) suggest another interesting policy idea: giving supermarkets incentives, such as tax breaks, if they offer online ordering. The rationale is that online ordering can reduce exposure to unhealthy foods, and this "pre-commitment" device can help people impose constraints on their own future behavior. Cohen and Babey (2012) suggest a policy that requires supermarkets to move unhealthy food to the backs of grocery stores or remove them from check-out aisles. They are consistent with the notion of "libertarian paternalism," which seeks to shift people towards behaviors they desire without limiting their freedom of choice. As discussed below, those policies are intended to help people with time-inconsistent preferences.

\subsection{Obesity externality and time-inconsistent preferences}

The rationale for government intervention seems to be largely based on the external costs obese people impose on others. One argument for public intervention to reduce obesity is that medical expenses tend to be higher for people with excess weight, meaning that they create fiscal externalities if they rely on public health insurance such as Medicare and Medicaid. However, as McCormic and Stone (2007) point out, it is not clear that lifetime healthcare costs of the obese will

2004). As mentioned below, this study controls for health by including obesity-related health variables (heart attack, stroke, current and past smoking, and diabetes).

${ }^{4}$ An interesting case of government intervention can be found in Japan, where a national law now requires companies and local governments to measure the waistlines of Japanese people between the ages of 40 and 74 as part of their annual checkups and imposes financial penalties on companies and local governments that fail to meet specific targets (Onishi, 2008).

${ }^{5}$ One survey reveals that $72 \%$ of people said that they oppose a tax on high-fat and high-sugar foods (Maris 2012).

${ }^{6}$ Food for home consumption is often excluded from state sales taxes (Gruber, 2007). 
be higher, since the obese tend to die earlier. Also, the fact that obese people die earlier implies that they end up receiving less social security or public pensions than non-obese people. For these reasons, the overall effect of obesity on government spending is ambiguous. The cost savings from early deaths from obesity are usually not discussed in the public health community (Philipson \& Posner, 2008). Another potential obesity externality exists in private health insurance markets. The externality arises when health insurance premiums do not adjust to reflect enrollee weight, such as when the obese and the non-obese are lumped into a single risk pool. But this can be solved if insurance companies require obese people to pay higher insurance premiums and does not call for public policies (Bhattacharya \& Sood, 2005; Philipson \& Posner, 2008). Indeed, some employers and health insurance companies already offer incentives for employers to engage in healthier behaviors (Mello \& Rosenthal, 2008). The case of obesity externalities and the policy implications are far from being closed.

Recent developments in behavioral economics have questioned the assumption of rationality and revealed that individuals may not be making optimal decisions, implying that government intervention is justified even in the absence of externalities. The standard economic view assumes that people can both make plans rationally and carry out those optimal plans, but in reality people are often unable to carry out long-term plans that involve self-control. ${ }^{7}$ Examples include smokers who are unable to quit and people who cannot give up current consumption and save enough for retirement. Behavioral economists argue that some consumption is not always the outcome of rational but rather of time-inconsistent behavior. Laibson (1997) formulated a model of hyperbolic discounting in which people have time-inconsistent preferences, which emphasize the present at the expense of long term. If people make systematic mistakes in consumption due to limited self-control and time-inconsistent preferences, it is possible for governments to improve social welfare, even in the absence of negative externalities. ${ }^{8}$

It is not surprising that people have difficulty eating healthily. Food brings immediate gratification, while health costs of overconsumption occur only in the future. Casual observations indicate that many people have time-inconsistent preferences when it comes to eating. It does not seem plausible to reconcile the prevalence of obesity with the size of diet and weight loss industries, and many go through bariatric surgery every year - these patterns in consumption behavior seem to contradict the rationality assumption.

\section{Data and empirical strategy}

I use micro-level data from the Behavioral Risk Factor Surveillance System Survey (BRFSS). This is a household-level random-digit telephone survey, collected by the US Government's National Center for Chronic Disease Prevention and Health. Our measure of life satisfaction is the response on a 4-point scale ranging from "Very satisfied" to "Very dissatisfied," to the question, "In general, how satisfied are you with your life?" The life satisfaction question has been asked

\footnotetext{
7 As Thaler and Sunstein argue in Nudge, "We do not claim that everyone who is overweight is necessarily failing to act rationally, but we do reject the claim that all or almost all Americans are choosing their diet optimally" (p. 7). Public welfare can be improved, they argue, if the government can discourage or "nudge" people from consuming unhealthy foods or overeating.

${ }^{8}$ In the model in Gruber and Koszegi (2001), people who have time-inconsistent preferences benefit if a tax is imposed because the tax serves as a commitment device that helps their self-control problem. Empirically, Gruber and Mullainathan (2005) find that people who are predicted to be smokers are happier when a cigarette tax is higher; presumably the higher price of cigarettes discourages them from smoking. Another empirical study that utilized subjective wellbeing and found that people suffer from self-control problems is Benesch et al. (2010), who find that heavy TV viewers' life satisfaction decrease when the number of TV channels increases.
} 
since 2005, so I use data from 2005, 2006, 2007, 2008, 2009, and 2010. ${ }^{9}$ Justifiable concerns that people's moods at the time of the survey can bias their reported life satisfaction still contribute to economists' reluctance to use subjective wellbeing, but many economists have started using subjective wellbeing data extensively. ${ }^{10}$ Recent studies include Stevenson and Wolfers (2009), who recorded a declining female happiness over time as regards income and happiness across countries; Sachs et al. (2010), who showed a robust relationship between subjective wellbeing and income; and Oswald and $\mathrm{Wu}(2010)$ who demonstrated that there is a close match between US life satisfaction scores and objective wellbeing indicators.

I restrict my analyses to people between 18 and 85 years old not residing in unincorporated US territories, and I exclude respondents who refused or were unsure of their response, or whose response is missing for any of the variables included in my analyses. The resulting sample size is 600,662 men and 864,557 women. Table 1 below shows the distribution and summary statistics of life satisfaction and obesity and overweightness for a sample of 1,465,219 individuals. ${ }^{11}$

Table 1. Life satisfaction and BMI $(\mathrm{N}=1,465,219)$

\begin{tabular}{cc}
\hline Life satisfaction & \\
Very satisfied & \\
Satisfied & $46.7 \%$ \\
Dissatisfied & $48.2 \%$ \\
Very dissatisfied & $4.1 \%$ \\
BMI (average=27.4, std. dev. $=5.4)$ : & $0.9 \%$ \\
Overweight (30>BMI $>25)$ & \\
Obese $($ BMI $>30)$ & $37.7 \%$ \\
\hline
\end{tabular}

A significant proportion of those interviewed for the BRFSS are satisfied with their life. $46 \%$ of the sample reported "very satisfied." 95\% of the sample reported "very satisfied" or "satisfied." The lowest level of life satisfaction is reported by only $0.9 \%$ of the sample. A standard measure of overweightness and obesity is body mass index (BMI), and a person is considered to be overweight if he has a BMI of 25 or more, and obese if his BMI is 30 or more. Because this study examines overweight and obesity, I exclude those whose BMI is less than 18.5, which is underweight. ${ }^{12} 64.3 \%$ of the sample is overweight, and $26.6 \%$ is obese. The average BMI is 27.4 , meaning that the average person in the sample is overweight. Table 2 below shows how people's weight categories and BMIs vary based on their life satisfaction. Average BMIs show that people tend to get heavier for each subsequent category of life satisfaction. People who are very satisfied with their life are much less likely to be obese than those who are very dissatisfied with their life (23.2\% vs. $38.0 \%)$.

\footnotetext{
${ }^{9}$ One limitation of this study is non-random response patterns, as BRFSS response rates vary by state and year but range from 27\% (New Jersey in 2007) to 69\% (Nevada in 2010), and willingness to respond may be related to key variables such as weight, health and life satisfaction.

${ }^{10}$ While psychologists tend to make a distinction between happiness and life satisfaction, economists tend to use the terms interchangeably (Graham et al., 2004). Not surprisingly, answers to happiness and life satisfaction questions are closely correlated (Graham, 2009).

${ }^{11}$ For both descriptive statistics and the regression analysis presented below, I apply the BRFSS survey weights to adjust for the probability of selection and non-response.

${ }^{12}$ Including the underweight does not substantially change the results.
} 
Table 2: Average BMI and obesity/overweight across life satisfaction

\begin{tabular}{lccc}
\hline & Obese & Overweight or obese & Average BMI \\
\hline Very satisfied & $23.2 \%$ & $62.0 \%$ & 27.0 \\
Satisfied & $28.9 \%$ & $65.9 \%$ & 27.8 \\
Dissatisfied & $35.3 \%$ & $69.4 \%$ & 28.7 \\
Very dissatisfied & $38.0 \%$ & $69.5 \%$ & 29.1 \\
\hline
\end{tabular}

Finally, Table 3 below shows average life satisfaction for different weight groups in the sample. Those with a healthy weight reported higher life satisfaction than the overweight (but not obese), and the overweight reported higher life satisfaction than the obese.

Table 3. Average life satisfaction across BMI categories

\begin{tabular}{ll}
\hline Healthy weight $(25>\mathrm{BMI} \geq 18.5)$ & 3.45 \\
Overweight but not obese $(30>\mathrm{BMI} \geq 25)$ & 3.43 \\
Obese $(\mathrm{BMI}>30)$ & 3.33 \\
\hline
\end{tabular}

Tables 2 and 3 above provide a visual test and show that heavier people are more likely to be dissatisfied with their life, and unhappy people are more likely to be heavy.

One obvious empirical issue is that life satisfaction and one's eating behavior are endogenous. The literature in psychology suggests that there is a reciprocal link between eating patterns and moods. ${ }^{13}$ Often called "emotional eating," where people may eat fat and sugary foods when feeling unhappy. Gardener et al. (2014) find the link between negative emotion and unhealthy food, and Fedorikhin and Patrick (2010) find that people are likely to choose healthy foods over unhealthy foods (grapes vs. chocolate) when they are in a positive mood. A high level of stress and a low level of life satisfaction are both predictors of weight gain (Korkila et al., 1998). However, other studies find that feeling joy is linked to increased consumption of indulgent foods (e.g., Bongers et al., 2013). Thus, the results of the effects of mood on eating are mixed, and it is not clear how people's life satisfaction changes their eating behavior. It would be desirable to have instrumental variables for one's weight status, but in this paper I do not address possible endogeneity, due to the lack of confidence in being able to find a good instrument. Thus, despite the wide range of controls included in the regression below, there still remains the possibility of

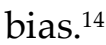

I take reported satisfaction with life as a proxy measure for individual utility and run the following regression equations:

$$
\begin{aligned}
& u_{i c}=\beta \text { Obese }_{i c}+\gamma X_{i c}+\theta_{c}+\varepsilon_{i c} \\
& u_{i c}=\beta \text { Overweight } i c+\gamma X_{i c}+\theta_{c}+\varepsilon_{i c}
\end{aligned}
$$

where $u_{i c}$ is life satisfaction for the individual $i$ in county $c$. I use two different weight measures: Obese (a dummy variable which takes the value of 1 if $\mathrm{BMI}>30$ ) and Overweight (a dummy variable which takes the value of 1 if $\mathrm{BMI}>25)$. $X_{i c}$ is socioeconomic and health controls, and $\theta_{c}$ is county fixed effects. Including county fixed effects alleviates concern about poverty

\footnotetext{
${ }^{13}$ Interestingly, even though the link is clearly reciprocal, recent evidence suggests that foods come first in the link between foods and moods. Hendy (2012) found that consumption of calories, saturated fat, and sodium was significantly associated with increase in negative mood two days later. White et al. (2013) find that eating fruit and vegetables one day is associated with a positive mood the next day.

${ }^{14}$ Another limitation of this study is measurement error in data because self-reported measures of weight and height rather than actual measures are used in the BRFSS.
} 
rates and lack of access to grocery stores, which are often associated with obesity. Table A in the appendix shows summary statistics of the variables used in the regression analysis. ${ }^{15}$ In addition to socioeconomic characteristics, I include obesity-related health variables (heart attack, stroke, current and past smoking, ${ }^{16}$ and diabetes) and month and year of interview.

Controlling for health and socioeconomic variables allows us to see the direct effects of overweightness. There are two possible opposing effects of being overweight once health and socioeconomic characteristics are included. First, people enjoy eating, so being overweight should have some beneficial effect on life satisfaction once the adverse health and economic effects are accounted for. Second, there may be a direct negative life satisfaction effect of being overweight, as overweight people may psychologically suffer from poor body image. In the regression analysis below, I analyze men and women separately. There is a good reason that the life satisfaction effects of overweight are different for men and women. Lay people seem to believe that looks matter more to women than to men, and, consistent with this view, Hamermesh and Abrevaya (2011) find that the effect of good looks on happiness is larger for women than for men. Thus, the negative life satisfaction effect of overweight may be larger for women than for men, if women psychologically suffer more from their body image. Also, if there are gender differences in how thinner people achieve more desirable outcomes in the labor market and marriage market (e.g., higher-income spouses), then that can contribute to the gender difference in the life satisfaction effects of overweight.

\section{Results}

I run three specifications: exogenous personal characteristics only, socioeconomic variables added, and health variables added. All regressions in this paper allow the error term to cluster at the county level. I use a linear probability model for ease of interpretation, but similar results are obtained from ordered probit models. In the first and second columns in Tables 4 below, the result shows a highly statistically significant negative correlation between life satisfaction and obesity for both men and women. Being obese is associated on a 4-point scale with a 0.07 points reduction in life satisfaction for men and 0.14 points for women. When socioeconomic characteristics are added, the association between life satisfaction and obesity remains statistically significant for both men and women, but the magnitude shrinks by 0.05 for women. Surprisingly, when health characteristics are added, the magnitudes remain virtually the same, indicating that the negative association is robust beyond one's health status. This finding contradicts that of Böckerman et al. (2014), who find that the effect of obesity disappears when health and functional status are controlled for.

Table 5 below shows the result when overweightness (BMI>25) is used instead of obesity. Interestingly, the negative association between life satisfaction and overweightness is not statistically significant for men when only exogenous variables are controlled for but becomes statistically significant when socioeconomic characteristics are controlled for.

\footnotetext{
${ }^{15}$ Unfortunately, household income is reported only in terms of income categories. The BRFSS reports household income in these ranges: less than $\$ 10,000, \$ 10,000-14,999, \$ 15,000-19,999, \$ 20,000-24,999, \$ 25,000-34,999$, \$35,000$49,999, \$ 50,000-74,999$, and $\$ 75,000$ or above. For estimation purposes, the respondent's income is first assumed to be the midpoint of the categories or $150 \%$ of the top category converted to 2010 year dollars using the CPI obtained from the Bureau of Labor Statistics. For the category “\$75,000 or more," I assigned an annual income of \$112,500 (150\% of $\$ 75,000$ ). The previous studies that used the BRFSS adopted the same method (Ruhm, 2005; Tekin et al., 2013).

${ }^{16}$ Smoking is included because there is evidence that individuals who quit smoking typically gain weight, and an increase in the price of cigarettes has contributed to a rise in obesity (Chou et al., 2004).
} 
Table 4a. Life satisfaction and obesity

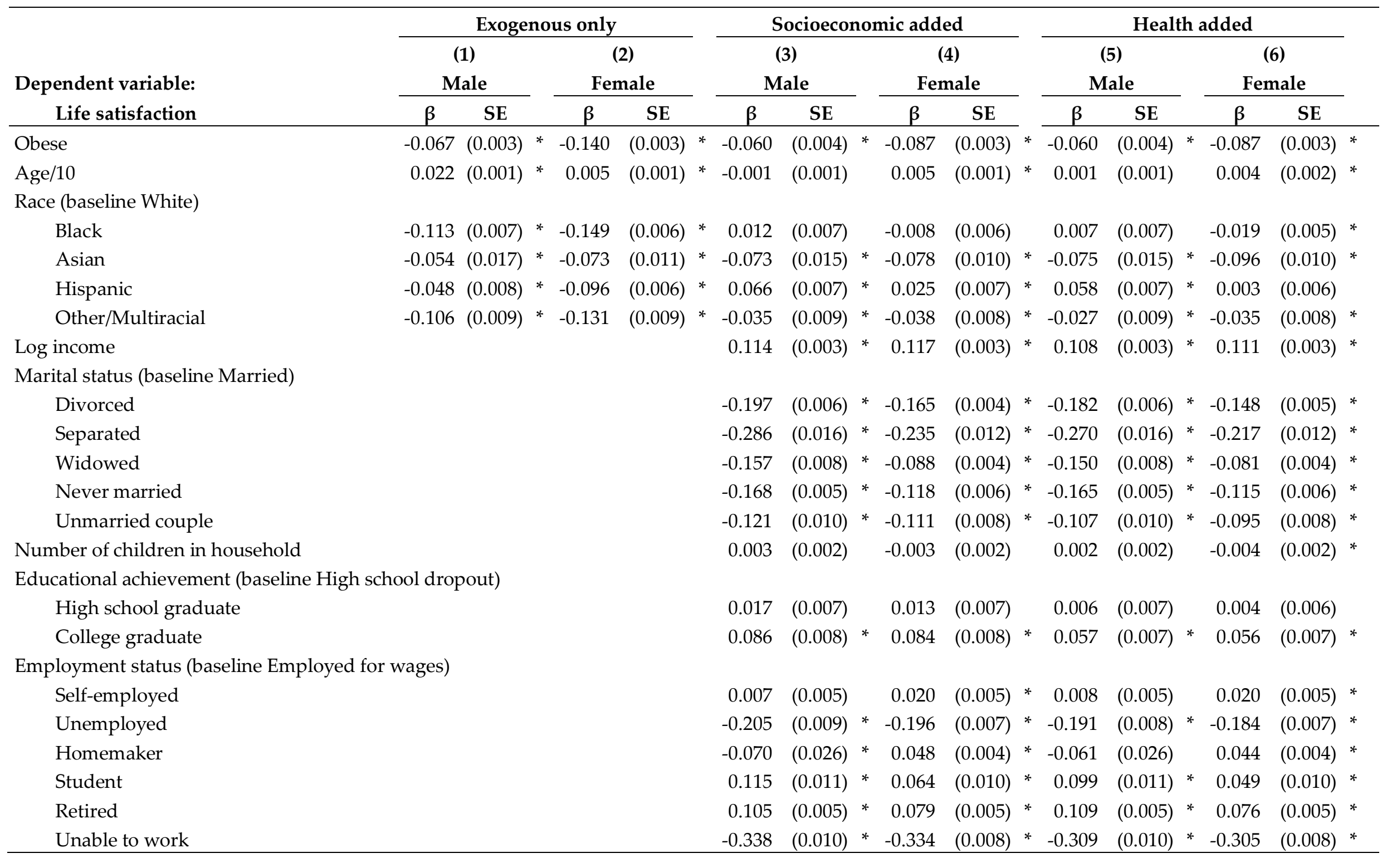


Table $4 \mathrm{~b}$. Life satisfaction and obesity

\begin{tabular}{|c|c|c|c|c|c|c|c|c|c|c|c|c|c|c|}
\hline \multirow{4}{*}{$\begin{array}{r}\text { Dependent variable: } \\
\text { Life satisfaction }\end{array}$} & \multicolumn{4}{|c|}{ Exogenous only } & \multicolumn{4}{|c|}{ Socioeconomic added } & \multicolumn{5}{|c|}{ Health added } & \\
\hline & \multirow{2}{*}{\multicolumn{2}{|c|}{$\begin{array}{c}(1) \\
\text { Male }\end{array}$}} & \multirow{2}{*}{\multicolumn{2}{|c|}{$\begin{array}{c}(2) \\
\text { Female }\end{array}$}} & \multirow{2}{*}{\multicolumn{2}{|c|}{$\begin{array}{c}(3) \\
\text { Male }\end{array}$}} & \multirow{2}{*}{\multicolumn{2}{|c|}{$\begin{array}{c}(4) \\
\text { Female }\end{array}$}} & \multirow{2}{*}{\multicolumn{3}{|c|}{$\begin{array}{c}(5) \\
\text { Male }\end{array}$}} & \multirow{2}{*}{\multicolumn{3}{|c|}{$\begin{array}{c}(6) \\
\text { Female }\end{array}$}} \\
\hline & & & & & & & & & & & & & & \\
\hline & $\beta$ & SE & $\beta$ & SE & $\beta$ & SE & $\beta$ & SE & $\beta$ & SE & & $\beta$ & SE & \\
\hline \multicolumn{15}{|l|}{ Health: } \\
\hline Heart attack & & & & & & & & & -0.046 & $(0.006)$ & * & -0.049 & $(0.008)$ & * \\
\hline Stroke & & & & & & & & & -0.057 & $(0.010)$ & * & -0.064 & $(0.009)$ & * \\
\hline Diabetes & & & & & & & & & -0.047 & $(0.005)$ & $*$ & -0.032 & $(0.004)$ & $*$ \\
\hline Current smoker & & & & & & & & & -0.133 & $(0.005)$ & * & -0.161 & $(0.004)$ & * \\
\hline Former smoker & & & & & & & & & -0.030 & $(0.004)$ & $*$ & -0.028 & $(0.003)$ & * \\
\hline No. of observations & \multicolumn{2}{|c|}{600,662} & & & \multicolumn{2}{|c|}{600,662} & \multicolumn{2}{|c|}{864,557} & \multicolumn{2}{|c|}{600,662} & \multicolumn{3}{|c|}{864,557} & \\
\hline
\end{tabular}

${ }^{*} \mathrm{p}<0.01$. Standard errors are clustered at the county level. All regressions include interview month and year dummies and county fixed effects. 
Table 5a. Life satisfaction and overweight

\begin{tabular}{|c|c|c|c|c|c|c|c|c|c|c|c|c|c|c|c|c|}
\hline \multirow{4}{*}{$\begin{array}{c}\text { Dependent variable: } \\
\text { Life satisfaction }\end{array}$} & \multicolumn{5}{|c|}{ Exogenous only } & & \multicolumn{7}{|c|}{ Socioeconomic added } & \multirow{3}{*}{\multicolumn{3}{|c|}{$\begin{array}{c}(5) \\
\text { Male } \\
\end{array}$}} \\
\hline & \multirow{2}{*}{\multicolumn{3}{|c|}{$\begin{array}{c}\text { (1) } \\
\text { Male }\end{array}$}} & \multirow{2}{*}{\multicolumn{2}{|c|}{$\begin{array}{c}(2) \\
\text { Female }\end{array}$}} & & \multirow[b]{3}{*}{$\beta$} & \multirow{2}{*}{\multicolumn{3}{|c|}{$\begin{array}{c}(3) \\
\text { Male }\end{array}$}} & \multirow{2}{*}{\multicolumn{3}{|c|}{$\begin{array}{c}(4) \\
\text { Female }\end{array}$}} & & & \\
\hline & & & & & & & & & & & & & & & & \\
\hline & $\beta$ & SE & & $\beta$ & SE & & & SE & & $\bar{\beta}$ & SE & & $\beta$ & SE & & $\beta$ \\
\hline Overweight & -0.001 & $(0.004)$ & & -0.105 & $(0.003)$ & * & -0.026 & $(0.004)$ & * & -0.067 & $(0.003)$ & * & -0.029 & $(0.004)$ & $*$ & -0.067 \\
\hline Age/10 & 0.021 & $(0.001)$ & $*$ & 0.007 & $(0.001)$ & * & -0.001 & $(0.001)$ & & 0.007 & $(0.001)$ & * & 0.002 & $(0.001)$ & & 0.006 \\
\hline \multicolumn{17}{|l|}{ Race (baseline White) } \\
\hline Black & -0.118 & $(0.007)$ & $*$ & -0.151 & $(0.006)$ & * & 0.009 & $(0.007)$ & & -0.008 & $(0.006)$ & & 0.005 & $(0.007)$ & & -0.018 \\
\hline Asian & -0.045 & $(0.017)$ & $*$ & -0.073 & $(0.011)$ & * & -0.070 & $(0.015)$ & * & -0.078 & $(0.010)$ & * & -0.073 & $(0.016)$ & $*$ & -0.096 \\
\hline Hispanic & -0.051 & $(0.008)$ & $*$ & -0.094 & $(0.006)$ & * & 0.065 & $(0.007)$ & * & 0.027 & $(0.007)$ & * & 0.058 & $(0.007)$ & * & 0.006 \\
\hline Other/Multiracial & -0.107 & $(0.009)$ & * & -0.132 & $(0.009)$ & * & -0.035 & $(0.009)$ & * & -0.038 & $(0.008)$ & * & -0.028 & $(0.009)$ & * & -0.034 \\
\hline Log income & & & & & & & 0.114 & $(0.003)$ & * & 0.117 & $(0.004)$ & * & 0.108 & $(0.003)$ & * & 0.111 \\
\hline \multicolumn{17}{|l|}{ Marital status (baseline Married) } \\
\hline Divorced & & & & & & & -0.197 & $(0.006)$ & * & -0.166 & $(0.005)$ & * & -0.181 & $(0.006)$ & * & -0.149 \\
\hline Separated & & & & & & & -0.284 & $(0.017)$ & * & -0.237 & $(0.013)$ & * & -0.269 & $(0.016)$ & * & -0.219 \\
\hline Widowed & & & & & & & -0.156 & $(0.008)$ & * & -0.088 & $(0.004)$ & * & -0.149 & $(0.008)$ & * & -0.081 \\
\hline Never married & & & & & & & -0.167 & $(0.006)$ & * & -0.120 & $(0.006)$ & * & -0.165 & $(0.006)$ & * & -0.117 \\
\hline Unmarried couple & & & & & & & -0.120 & $(0.010)$ & * & -0.110 & $(0.008)$ & * & -0.107 & $(0.010)$ & * & -0.094 \\
\hline Number of children in household & & & & & & & 0.003 & $(0.002)$ & & -0.003 & $(0.002)$ & & 0.002 & $(0.002)$ & & -0.004 \\
\hline \multicolumn{17}{|c|}{ Educational achievement (baseline High school dropout) } \\
\hline High school graduate & & & & & & & 0.016 & $(0.007)$ & & 0.014 & $(0.007)$ & & 0.005 & $(0.007)$ & & 0.004 \\
\hline College graduate & & & & & & & 0.089 & $(0.008)$ & * & 0.084 & $(0.007)$ & * & 0.059 & $(0.007)$ & * & 0.056 \\
\hline \multicolumn{17}{|c|}{ Employment status (baseline Employed for wages) } \\
\hline Self-employed & & & & & & & 0.009 & $(0.005)$ & & 0.020 & $(0.005)$ & * & 0.009 & $(0.005)$ & & 0.020 \\
\hline Unemployed & & & & & & & -0.206 & $(0.008)$ & * & -0.197 & $(0.007)$ & * & -0.192 & $(0.008)$ & $*$ & -0.184 \\
\hline Homemaker & & & & & & & -0.070 & $(0.026)$ & * & 0.047 & $(0.004)$ & * & -0.062 & $(0.026)$ & & 0.044 \\
\hline Student & & & & & & & 0.116 & $(0.011)$ & * & 0.063 & $(0.010)$ & * & 0.100 & $(0.011)$ & $*$ & 0.047 \\
\hline Retired & & & & & & & 0.106 & $(0.005)$ & * & 0.079 & $(0.005)$ & * & 0.110 & $(0.005)$ & * & 0.076 \\
\hline Unable to work & & & & & & & -0.343 & $(0.010)$ & * & -0.340 & $(0.008)$ & $*$ & -0.313 & $(0.010)$ & $*$ & -0.310 \\
\hline
\end{tabular}


Table 5b. Life satisfaction and overweight

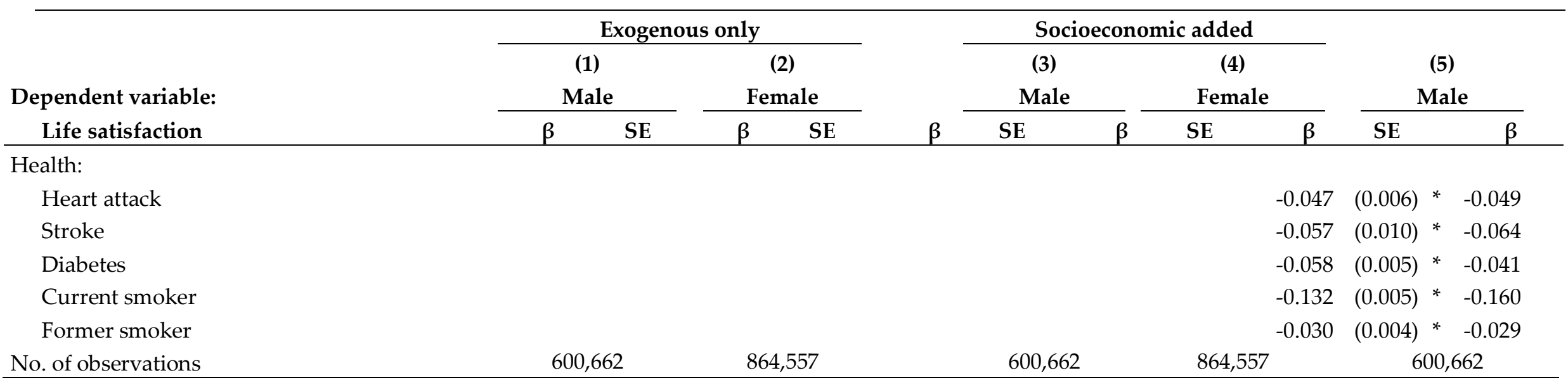


This is evidence that, as traditional economic theory suggests, many overweight men are deriving utility from overeating. That is, the negative effect of overweight (i.e., poor health) is offset by the positive effect (i.e., the pleasure of eating). However, for women, being overweight is negatively associated with life satisfaction, whether or not socioeconomic and health characteristics are controlled for.

Overall, the results above demonstrate that being obese or overweight is associated with lower life satisfaction beyond its effects through health and socioeconomic status. Whatever people get in return for being overweight or obese may not be worth the tradeoff, whether it is health, social, or economic. Of course, we should keep in mind that the results above do not establish causality, but a simple comparison of the coefficients reveals that the magnitude of the negative association between life satisfaction and being heavy is not trivial. The estimate of the tradeoffs between income and being overweight/obese that will leave people, on average, equally happy, can be calculated by using the coefficients from the regressions. If we naively assume that the effects of the coefficients are causal and use the coefficients from columns 5 and 6 in Table 4 and Table 5 above, with the sample median income of $\$ 49,347$, being obese is equivalent to losing $\$ 20,998$ (or $42.6 \%$ of income) for men and $\$ 26,901$ (or $54.5 \%$ of income) for women, and being overweight is equivalent to losing $\$ 11,509$ (or $23.3 \%$ of income) for men and $\$ 22,384$ (or $45.4 \%$ of income) for women. These figures are shown in Table 6 below.

Table 6. Illustrative valuations of obesity and overweight

\begin{tabular}{lcccc}
\hline & \multicolumn{2}{c}{ \% income equivalence } & \multicolumn{2}{c}{ Median income $\$ 49,347$} \\
\hline & Men & Women & Men & Women \\
Obese & $42.6 \%$ & $54.5 \%$ & $\$ 20,998$ & $\$ 26,901$ \\
Overweight & $23.3 \%$ & $45.4 \%$ & $\$ 11,509$ & $\$ 22,384$ \\
\hline
\end{tabular}

Note: Values are calculated from columns 5 and 6 of Table 4 and Table 5 above. The income equivalence is calculated as [exp(coefficient on obesity or overweight/coefficient on log income)-1], which is then multiplied by median income $\$ 49,347$.

Of course, they are only suggestive, as income and life satisfaction are also endogenous, but, given that many people spend a significant portion of their income on weight-loss related goods and services, ${ }^{17}$ they are not entirely inconceivable.

\section{Conclusions}

There is a question whether governments should intervene to reduce obesity, and the debate on government intervention often focuses on obesity as a public health issue. This paper focuses on obesity as a welfare issue. Many economists consider that rational individuals trade off health for pleasure and convenience, and oppose government intervention. Philipson and Posner (2008) summarize the issue with this line of philosophy: "Intervention that considers such tradeoffs unworthy of consideration is paternalistic." Nevertheless, other economists think that overweight people are not necessarily making optimal choices when it comes to eating. People often overeat because enjoyment of a meal is immediate, while the consequent weight gain is delayed, and are unable to control their short-term desires for their own long-term wellbeing.

\footnotetext{
${ }_{17}$ In 2015, the average cost of gastric bypass surgery in the United States was approximately $\$ 24,000$ (Bariatric Surgery Source, 2015). The size of the US weight loss market was $\$ 64$ billion in 2014 (Kell, 2015).
} 
This paper finds a robust negative association between life satisfaction and body weight. The author wishes to emphasize that the results above do not establish causality, but they provide some insights into the question - do people eat food beyond the point that is optimal, or are overweight people contentedly fat? The findings suggest that overweight and obese people may not be always making a freely chosen tradeoff, and utility gain from overeating may be more than offset by the disutility from being overweight. While the rationality assumption and the argument for anti-paternalism should not be dismissed, anti-obesity policy should be evaluated not only in the context of the healthcare costs but also in the context of wellbeing. If many overweight people are struggling with self-control problems, effective anti-obesity policies may lead to higher life satisfaction among them.

\section{Acknowledgments}

The author thanks an anonymous referee for useful comments.

\section{Author}

Masanori Kuroki

Arkansas Tech University

mkuroki@atu.edu

\section{Publishing Timeline}

Received 10 March 2016

Accepted 24 July 2016

Published 14 September 2016

\section{References}

Bariatric Surgery Source. (2015). Gastric bypass surgery cost by state: 2015 (and how to make it affordable). www.bariatric-surgery-source.com/cost-bariatric-surgery.html

Becker, G. (2005). Response on obesity and advertising. The Becker-Posner Blog. http://www.beckerposner-blog.com/2005/12/response-on-obesity-and-advertising-becker/comments/page/1/

Becker, G., \& Murphy, K. (1988). A theory of rational addiction. Journal of Political Economy, 96, 675-700. http://dx.doi.org/10.1086/261558

Benesch C., Frey, B. S. \& Stutzer, A. (2010). TV channels, self-control and happiness. The B.E. Journal of Economic Analysis \& Policy, 10(1), 1-35. http://dx.doi.org/10.2202/1935-1682.2119

Bhattacharya, J., \& Sood, N. (2005). Health insurance and the obesity externality (NBER Working Paper No. 11529).

Böckerman, P., Johansson, E., Saarni, S. I., \& Saarni, S. E. (2014). The negative association of obesity with subjective well-being: Is it all about health? Journal of Happiness Studies, 15(4), 857-867.

http://dx.doi.org/10.1007/s10902-013-9453-8

Bongers, P., Jansen, A., Havermans, R., Roefs, A., \& Nederkoorn C. (2013). Happy eating: The underestimated role of overeating in a positive mood. Appetite, 67(1), 74-80.

http://dx.doi.org/10.1016/j.appet.2013.03.017

Brownell, K. D., Farley, T., Willett, W. C., Popkin, B. M., Chaloupka, F. J., Thompson, J. W., \& Ludwig, D. S. (2009). The public health and economic benefits of taxing sugar-sweetened beverages. Health Policy Report of the New England Journal of Medicine, 361(16), 1599-1605.

http://dx.doi.org/10.1056/NEJMhpr0905723

Brunello, G., \& D’Hombres, B. (2007). Does body weight affect wages? Evidence from Europe. Economics and Human Biology, 5(1), 1-19. http://dx.doi.org/10.1016/j.ehb.2006.11.002

Caliendo, M., \& Lee, W. (2013). Fat chance! Obesity and the transition from unemployment to employment. Economics and Human Biology, 11(2), 121-133. http://dx.doi.org/10.1016/j.ehb.2012.02.002 
Cawley, J. (2004). The impact of obesity on wages. Journal of Human Resources, 39(2), 451-474. http://dx.doi.org/10.2307/3559022

Centers for Disease Control and Prevention (2015). Health, United States, 2015, table 53. http://www.cdc.gov/nchs/fastats/obesity-overweight.htm

City of Boston. (2011). Mayor Menino issues order to end sugary drink sales on city property. http://www.cityofboston.gov/news/default.aspx?id=5051

Cohen, D. A., \& Babey, S. H. (2012). Cash at the candy register: A risk factor for obesity and chronic disease. New England Journal of Medicine, 367(15), 1381-1383. http://dx.doi.org/10.1056/NEJMp1209443

Cutler, D. M., Glaeser, E. L., \& Shapiro, J. M. (2003). Why have Americans become more obese? Journal of Economic Perspectives, 17(3), 93-118. http://dx.doi.org/10.1257/089533003769204371

Downs, J. S., Loewenstein, G., \& Wisdom, J. (2009). Strategies for promoting healthier food choices. American Economic Review, 99(2), 159-164. http://dx.doi.org/10.1257/aer.99.2.159

Dragone, D. (2009). A rational eating model of binges, diets and obesity. Journal of Health Economics, 28(4), 799-804. http://dx.doi.org/10.1016/j.jhealeco.2009.06.001

Fedorikhin, A., \& Patrick, V. M. (2010). Positive mood and resistance to temptation: The interfering influence of elevated arousal. Journal of Consumer Research, 37(4), 698-711.

http://dx.doi.org/10.1086/655665

Finkelstein, E. A., Ruhm, C. J., \& Kosa, K. M. (2005). Economic causes and consequences of obesity. Annual Review of Public Health, 26, 239-257. http://dx.doi.org/10.1146/annurev.publhealth.26.021304.144628

Forste, R., \& Moore, E. (2012). Adolescent obesity and life satisfaction: Perceptions of self, peers, family, and school. Economics and Human Biology, 10(4), 385-394. http://dx.doi.org/10.1016/j.ehb.2012.04.008

Gardner, M. P., Wansink, B., Kim, J., \& Park, S. (in press). Better moods for better eating? How mood influences food choice. Journal of Consumer Psychology. http://dx.doi.org/10.1016/j.jcps.2014.01.002

Graham, C. (2009). Happiness around the world: The paradox of happy peasants and miserable millionaires. New York, NY: Oxford University Press. http://dx.doi.org/10.1093/acprof:osobl/9780199549054.001.0001

Graham, C., Eggers, A., \& Sukhtankar, S. (2004). Does happiness pay? An exploration based on panel data from Russia. Journal of Economic Behavior and Organization, 55, 319-342. http://dx.doi.org/10.1016/s0167-2681(04)00047-2

Graham, C., \& Felton, A. (2005). Variance in obesity across cohorts and countries: A norms-based explanation using happiness surveys (CSED Working Paper No. 42). Washington, D. C.: The Brookings Institution.

Grossman, M., Tekin, E., \& Wada, R. (2014). Food prices and body fatness among youths. Economics and Human Biology, 12, 4-19. http://dx.doi.org/10.1016/j.ehb.2013.10.003

Gruber, J. (2007). Commentary: Sin taxes (Unpublished manuscript).

Gruber, J., \& Koszegi, B. (2001). Is addiction "rational"? Theory and evidence. Quarterly Journal of Economics, 116(4), 1261-1303. http://dx.doi.org/10.1162/003355301753265570

Gruber J. H., \& Mullainathan, S. (2005). Do cigarette taxes make smokers happier? The B.E. Journal of Economic Analysis \& Policy, 5(1), 1-45. http://dx.doi.org/10.1515/1538-0637.1412

Hamermesh, D. (2004). Subjective outcomes in economics. Southern Economic Journal, 71, 2-11. http://dx.doi.org/10.2307/4135306

Hamermesh, D. S., \& Abrevaya, J. (2011). Beauty is the promise of happiness? (NBER Working Paper No. 17327).

Hendy, H. M. (2012). Which comes first in food-mood relationships, foods or moods? Appetite, 58(2), 771775. http://dx.doi.org/10.1016/j.appet.2011.11.014

Jacobson, M. F., \& Brownell, K. D. (2000). Small taxes on soft drinks and snack foods to promote health. American Journal of Public Health, 90(6), 854-857. http://dx.doi.org/10.2105/AJPH.90.6.854

Katsaiti, M. (2012). Obesity and happiness. Applied Economics, 44(31), 4101-4114. http://dx.doi.org/10.1080/00036846.2011.587779

Kell, J. (2015). Lean times for the diet industry. Fortune. http://fortune.com/2015/05/22/lean-times-for-thediet-industryl 
Korkeila, M., Kaprio, J., Rissanen, A., Koshenvuo, M., \& Sörensen, T. I. (1998). Predictors of major weight gain in adult Finns: Stress, life satisfaction and personality traits. International Journal of Obesity and Related Metabolic Disorders, 22(10), 949-957. http://dx.doi.org/10.1038/sj.ijo.0800694

Laibson, D. (1997). Golden eggs and hyperbolic discounting. The Quarterly Journal of Economics, 112(2), 443-478. http://dx.doi.org/10.1162/003355397555253

Lakdawalla, D., \& Philipson, T. (2009). The growth of obesity and technological change: A theoretical and empirical examination. Economics and Human Biology, 7(3), 283-293.

http://dx.doi.org/10.1016/j.ehb.2009.08.001

Lindeboom, M., Lundborg, P., \& van der Klaauw, B. (2010). Assessing the impact of obesity on labor market outcomes. Economics and Human Biology, 8(3), 309-19.

http://dx.doi.org/10.1016/j.ehb.2010.08.004

Liu, P. J., Wisdom, J., Roberto, C. A., Liu, L. J., \& Ubel, P. A. (in press). Using behavioral economics to design more effective food policies to address obesity. Applied Economic Perspectives and Policy. http://dx.doi.org/10.1093/aepp/ppt027

Maris, D. (2012). Is a fat tax in America's future? Forbes. http://www.forbes.com/sites/davidmaris/2012/04/19/is-a-tax-on-obesity-in-americas-future/

McCormick, B., \& Stone, I. (2007). Economic costs of obesity and the case for government intervention. Obesity Reviews, 8, 161-164. http://dx.doi.org/10.1111/j.1467-789X.2007.00337.x

Mello, M. M., \& Rosenthal, M. B. (2008). Wellness programs and lifestyle discrimination: The legal limits. New England Journal of Medicine, 359(2), 192-199. http://dx.doi.org/10.1056/NEJMhle0801929

Morris, S. (2007). The impact of obesity on employment. Labour Economics, 14(3), 413-433. http://dx.doi.org/10.1016/j.labeco.2006.02.008

Onishi, N. (2008, June 13). Japan, seeking trim waists, measures millions. New York Times.

Oswald, A. J., \& Powdthavee, N. (2007). Obesity, unhappiness, and the challenge of affluence: Theory and evidence. Economic Journal, 117(6), 441-454. http://dx.doi.org/10.1111/j.1468-0297.2007.02077_1.x

Oswald, A. J., \& Wu, S. (2010). Objective confirmation of subjective measures of human well-being: Evidence from the U.S.A. Science, 327(5965), 576-579. http://dx.doi.org/10.1126/science.1180606

Philipson, T. J., \& Posner, R. A. (2008). Is the obesity epidemic a public health problem? A review of Zoltan J. Acs and Alan Lyles's obesity, business and public policy. Journal of Economic Literature, 46(4), 974-82. http://dx.doi.org/10.1257/jel.46.4.974

Powell, L. M., \& Chaloupka, F. J. (2009). Food prices and obesity: Evidence and policy implications for taxes and subsidies. Milbank Quarterly, 87(1), 229-57. http://dx.doi.org/10.1111/j.14680009.2009.00554.x

Public Health England (2015). UK and Ireland prevalence and trends. https://www.noo.org.uk/NOO about obesity/adult obesity/UK prevalence and trends

Roberts, R. E., Deleger, S., Strawbridge, W. J., \& Kaplan, G. A. (2003). Prospective association between obesity and depression: Evidence from the Alameda County Study. International Journal of Obesity, 27, 514-521. http://dx.doi.org/10.1038/sj.ijo.0802204

Roehling, M., Roehling, P., \& Pichler, S. (2007). The relationship between body weight and perceived weight-related employment discrimination: The role of sex and race. Journal of Vocational Behavior, 7, 300-318. http://dx.doi.org/10.1016/j.jvb.2007.04.008

Ruhm, C., J. (2005). Healthy living in hard times. Journal of Health Economics, 24(2), 341-363. http://dx.doi.org/10.1016/j.jhealeco.2004.09.007

Sachs, D. W., Stevenson, B., \& Wolfers, J. (2010). Subjective well-being, income, economic development and growth (NBER Working Paper No. 16441).

Stevenson, B., \& Wolfers, J. (2009). The paradox of declining female happiness. American Economic Journal: Economic Policy, 1(2), 190-225. http://dx.doi.org/10.1257/pol.1.2.190

Stigler, G. J. (1961). The economics of information. Journal of Political Economy, 69(3), 213-225. http://dx.doi.org/10.1086/258464

Tekin, E., McClellan, C., \& Minyard, K. J. (2013). Health and health behaviors during the worst of times: Evidence from the Great Recession (NBER Working Paper No. 19234). 
Thaler, R. H., \& Sunstein, C. R. (2008). Nudge: Improving decisions about health, wealth, and happiness. New Haven, CT: Yale University Press.

Wadsworth T., \& Pendergast, P. M. (2014). Obesity (sometimes) matters: The importance of context in the relationship between obesity and life satisfaction. Journal of Health and Social Behavior, 55(2), 196-214. http://dx.doi.org/10.1177/0022146514533347

White, B. A., Horwath, C. C., \& Conner, T. S. (2013). Many apples a day keep the blues away: Daily experiences of negative and positive affect and food consumption in young adults. British Journal of Health Psychology, 18(4) 782-798. http://dx.doi.org/10.1111/bjhp.12021 


\section{Appendix}

\section{Table A. Summary statistics}

\begin{tabular}{|c|c|}
\hline Age & 45.6 \\
\hline \multicolumn{2}{|l|}{ Gender: } \\
\hline Male & $41.0 \%$ \\
\hline Female & $59.0 \%$ \\
\hline \multicolumn{2}{|l|}{ Race: } \\
\hline White (non-Hispanic) & $70.6 \%$ \\
\hline Black (non-Hispanic) & $9.6 \%$ \\
\hline Asian (non-Hispanic) & $3.3 \%$ \\
\hline Hispanic & $12.4 \%$ \\
\hline Other/Multiracial (non-Hispanic) & $4.1 \%$ \\
\hline \multicolumn{2}{|l|}{ Marital status: } \\
\hline Married & $64.2 \%$ \\
\hline Divorced & $8.8 \%$ \\
\hline Separated & $1.9 \%$ \\
\hline Widowed & $4.6 \%$ \\
\hline Never married & $16.7 \%$ \\
\hline Unmarried couple & $3.8 \%$ \\
\hline Number of children in household & 0.86 \\
\hline \multicolumn{2}{|l|}{ Educational achievement: } \\
\hline High school dropout & $8.4 \%$ \\
\hline High school graduate & $52.2 \%$ \\
\hline College graduate & $39.4 \%$ \\
\hline \multicolumn{2}{|l|}{ Employment status: } \\
\hline Employed for wages & $56.1 \%$ \\
\hline Self-employed & $9.1 \%$ \\
\hline Unemployed & $5.8 \%$ \\
\hline Homemaker & $7.0 \%$ \\
\hline Student & $4.0 \%$ \\
\hline Retired & $13.7 \%$ \\
\hline Unable to work & $4.3 \%$ \\
\hline Mean annual Income: & $\$ 53,643$ \\
\hline Median annual Income: & $\$ 49,347$ \\
\hline \multicolumn{2}{|l|}{ Health: } \\
\hline Heart attack & $3.7 \%$ \\
\hline Stroke & $2.3 \%$ \\
\hline Diabetes & $7.9 \%$ \\
\hline Current smoker & $18.1 \%$ \\
\hline Former smoker & $25.3 \%$ \\
\hline
\end{tabular}

